\title{
The Influence of Nutritional Assessment on the Outcome of Ostomy Takedown
}

\author{
Min Sang Kim, Ho Kun Kim, Dong Yi Kim, Jae Kyun Ju \\ Department of Surgery, Chonnam National University Hospital, Gwangju, Korea
}

Purpose: Ostomy takedown is often considered a simple procedure without intention; however, it is associated with significant morbidity. This study is designed to evaluate factors predicting postoperative complications in the ostomy takedown in view of metabolism and nutrition.

Methods: A retrospective, institutional review-board-approved study was performed to identify all patients undergoing takedown of an ostomy from 2004 to 2010.

Results: Of all patients (150), 48 patients (32\%; male, 31; female, 17) had complications. Takedown of an end-type ostomy showed a high complication rate; complications occurred in $55.9 \%$ of end-type ostomies and $15.7 \%$ of loop ostomies ( $<<$ $0.001)$. Severe adhesion was also related to a high rate of overall complication $(41.3 \%)(\mathrm{P}=0.024)$. In preoperative work-up, ostomy type was not significantly associated with malnutrition status. However, postoperatively severe malnutrition level (albumin $<2.8 \mathrm{mg} / \mathrm{dL}$ ) was statistically significant in increasing the risk of complications $(72.7 \%, \mathrm{P}=0.015)$. In particular, a significant postoperative decrease in albumin $(>1.3 \mathrm{mg} / \mathrm{dL})$ was associated with postoperative complications, particularly surgical site infection (SSI). Marked weight loss such as body mass index downgrading may be associated with the development of complications.

Conclusion: A temporary ostomy may not essentially result in severe malnutrition. However, a postoperative significant decrease in the albumin concentration is an independent risk factor for the development of SSI and complications.

Keywords: Ostomy takedown; Malnutrition; Albumins; Surgical site infection; Complication

\section{INTRODUCTION}

Since 1795 colostomies have been performed successfully, and the ostomy has been available as a surgical option in the treatment of complicated gastrointestinal diseases [1-3]. The ostomy has various metabolic and functional outcomes according to the site or the type and results in nutritional problems. Stoma takedown is often considered a "simple" procedure without intention; however,

Received: March 16, 2012 • Accepted: June 20, 2012

Correspondence to: Jae Kyun Ju, M.D.

Department of Surgery, Chonnam National University Hospital, Chonnam National University Medical School, 42 Jebong-ro, Dong-gu, Gwangju 501-757, Korea

Tel: +82-62-220-6456, Fax: +82-62-227-1635

E-mail: jkju@jnu.ac.kr

(C) 2012 The Korean Society of Coloproctology

This is an open-access article distributed under the terms of the Creative Commons Attribution NonCommercial License (http://creativecommons.org/licenses/by-nc/3.0) which permits unrestricted noncommercial use, distribution, and reproduction in any medium, provided the original work is properly cited. as clearly demonstrated in the literature, it is associated with significant morbidity, as high as 5 to $39 \%[4,5]$. Several factors, such as the patient' underlying disease, the type of ostomy, and the operation time, were reported to be related to postoperative complications [6-8].

Ostomy patients have more nutritional needs because many patients are nutritionally compromised. Grimble [9] reported that in patients with malnutrition, perioperative support was used to decrease the risk of postoperative anastomotic leakage and infectious complications. However, in the aspect of nutritional status, there have been few studies of the influence of takedown on outcome. Albumin is a commonly used and reliable indicator of nutritional status [10]. Hypoalbuminemia is a predictor of death, long hospital stay, and poor surgical outcome and is also associated with the development of complications following gastrointestinal surgery [11-13]. However, there is limited information regarding the effect of hypoalbuminemia on the development of postoperative complications following ostomy takedown, as ostomy formation has been considered without intention by surgeons. This study aimed 
to investigate the effect of nutritional status, especially albumin, on the development of complications following ostomy takedown.

\section{METHODS}

A retrospective, institutional-review-board-approved study was performed to identify all patients undergoing takedown of ostomies from 2004 to 2010. We collected data, including patient demographics, nutritional status, management, and subsequent outcome. Of 185 patients, pediatric patients and patients undergoing

Table 1. Adhesion tenacity scoring system

\begin{tabular}{ll}
\hline Score & \multicolumn{1}{c}{ Descripation } \\
\hline 1 & No adhesions \\
2 & Filmy adhesions, easily broken manually \\
3 & Dense adhesions requiring blunt dissection to separate viscera \\
4 & $\begin{array}{c}\text { Very dense adhesions, viscera matted to surface, requiring } \\
\text { sharp dissection to separate viscera }\end{array}$ \\
\hline
\end{tabular}

complicated procedures, including other gastrointestinal surgery during the period with a temporary ostomy, were excluded, and 150 consecutive patients were enrolled.

For evaluation of nutritional status, interval albumin (discharge level after the primary operation, pre-takedown level, and posttakedown level), change of body weight and body mass index (BMI) between the primary operation and takedown, and change of total lymphocyte counts (TLC) were examined. Nutritional status was assessed by a nutritional support team. Albumin and TLC were rated on a 4-degree scale (albumin: good, $\geq 3.5 \mathrm{mg} / \mathrm{dL}$; mild, 3.2 to $3.5 \mathrm{mg} / \mathrm{dL}$; moderate, 2.8 to $3.2 \mathrm{mg} / \mathrm{dL}$; severe, $<2.8 \mathrm{mg} / \mathrm{dL}$; TLC: good, $\geq 1,500 / \mathrm{mm}^{3}$; mild, 1,200 to $1,500 / \mathrm{mm}^{3}$; moderate, 800 to $1,200 / \mathrm{mm}^{3}$; severe, $\left.<800 / \mathrm{mm}^{3}\right)$. BMI was also rated on 4 -degree scale, low $\left(<18.5 \mathrm{~kg} / \mathrm{m}^{2}\right)$, normal ( 18.5 to $\left.25 \mathrm{~kg} / \mathrm{m}^{2}\right)$, overweight $\left(25\right.$ to $\left.30 \mathrm{~kg} / \mathrm{m}^{2}\right)$ and obese $\left(>30 \mathrm{~kg} / \mathrm{m}^{2}\right)$, and changes of BMI and body weight were examined. An assessment of adhesion tenacity was performed using the grading system proposed by Garrard et al. [14] (moderate, score 2; severe, score 3 and 4) (Table 1).

Complications were evaluated in all patients over a 30 -day postoperative time period from the time of stoma takedown and were

Table 2. Demographics of patients $(n=150)$

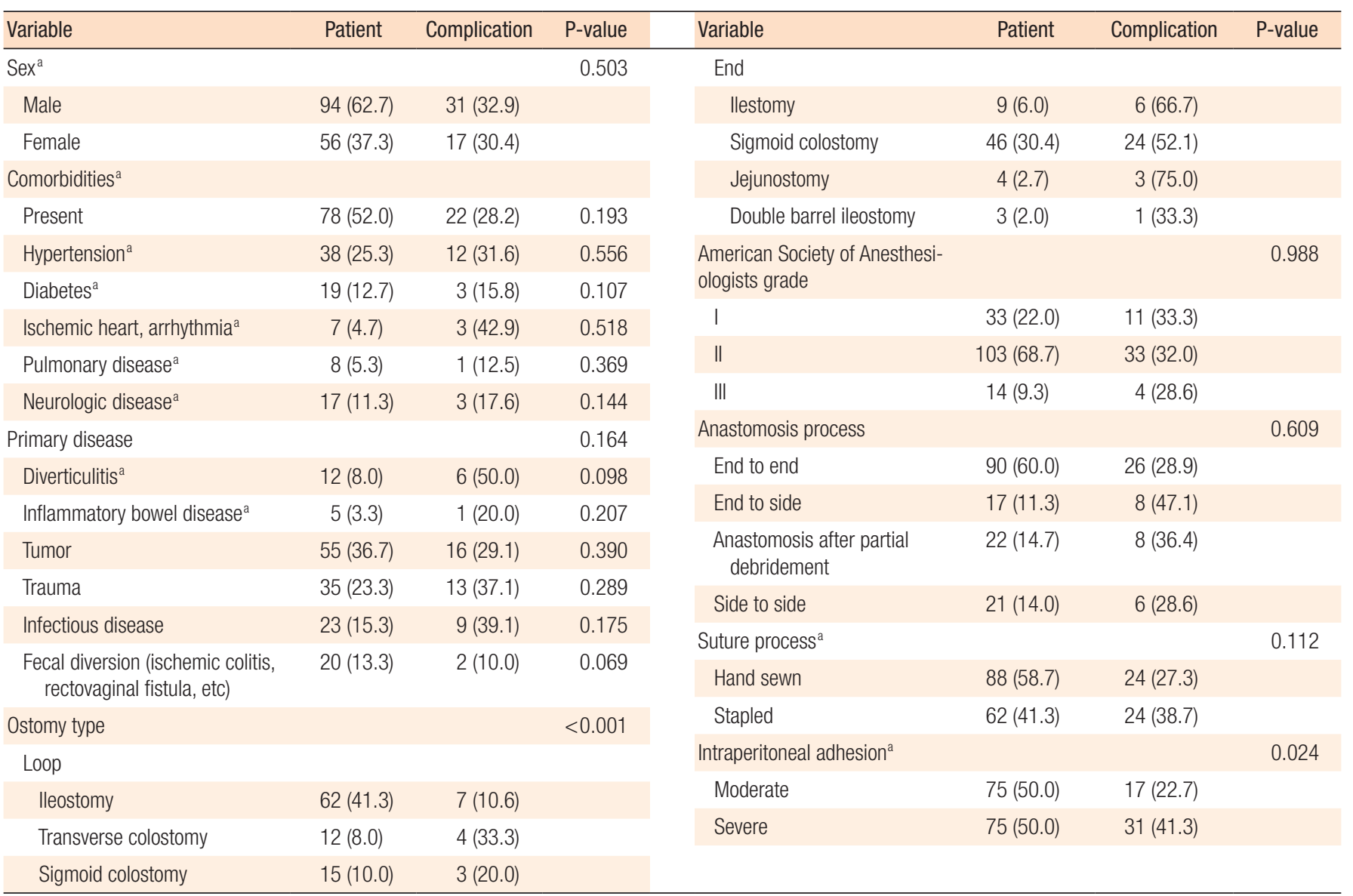

Values are presented as number (\%).

aFischer exact test. 
defined as abnormal events resulting in morbidities. Postoperative ileus was defined as weak bowel sound and no flatus expelled until 7 days postoperative time and nasogastric tube insertion to decompress because of nausea and vomitus since the start of diet. Surgical site infection (SSI) was defined as pus discharge from a surgical site or wound dehiscence. Anastomotic leakage was defined as secondary peritonitis, contrast media leak on radiologic study, and enterocutaneous fistula. Dietary status was defined as 3 stepsN.P.O., water feeding, and soft diet. Preoperative physiologic status was assessed using the American Society of Anesthesiologists (ASA) score. Operation time was the time period from skin incision to skin suture.

Data were recorded and analyzed using PASW ver. 18.0 (IBM Co., Armonk, NY, USA). Statistical analysis was performed using the chi-squared or the Fischer exact test for categoric variables and the Student's t-test or the Mann-Whitney rank-sum test for continuous variables. Multivariate logistic regression selected significant factors in relation to overall incidence of complications and each incidence of complication. The optimal cut-off value for assessing the postoperative decrease in albumin was determined by using a receiver-operating characteristic (ROC) curve analysis. Statistical significance was set at a P-value of less than 0.05 .

\section{RESULTS}

Of all patients, 48 patients (32\%; male, 31 ; female, 17) had complications. Table 2 lists the patient demographics and relationship to the incidence of complications. Ostomy type and intraperitoneal adhesion were significant factors. Takedown of an end-type ostomy showed a high complication rate; complications occurred in $55.9 \%$ of end ostomies and $15.7 \%$ of loop ostomies $(\mathrm{P}<0.001)$. Severe adhesion was also related to a high rate of overall complications (41.3\%, $\mathrm{P}=0.024)$. Ileus was the most important complication in severe adhesion cases $(\mathrm{P}=0.012)$.

Several factors which were related to nutritional status showed some interesting results (Table 3 ). One hundred eight patients (72.0\%) had maintained their BMI level during the period of observation. Downgraded change was observed in 22 patients (14.7 $\%)$; of these, 14 patients had complications $(\mathrm{P}=0.004)$. Body weight trended to decrease moderately to severely in patients with complications. Pre- and post-BMI were not related with the development of complications; however, downward shift of BMI was related significantly with complications $(\mathrm{P}=0.002)$. Regarding serum albumin concentration, preoperative level was not significant while postoperative level and postoperative prominent decrement were associated with the development of overall complications $(\mathrm{P}=$ $0.015,<0.001$ ) (Table 3).

Next to be considered is the impact of serum albumin concentration as a marker of the development of complications. In preoperative work-up, ostomy type was not so significantly associated with the status of malnutrition. However, postoperatively, severe malnutrition (albumin $<2.8 \mathrm{mg} / \mathrm{dL}$ ) was statistically significant in increasing the risk of complications $(72.7 \%, \mathrm{P}=0.015)$. The best cut-off value for the postoperative decrease in albumin was determined by using ROC curves. A decrease of more than $1.3 \mathrm{mg} / \mathrm{dL}$ was highly related to the risk of complications $(\mathrm{P}<0.001)$.

\section{Ileus}

Postoperative ileus occurred in 21 patients (14\%). Table 4 lists sig-

Table 3. Nutritional status assessment

\begin{tabular}{|c|c|c|c|}
\hline Variable & $\begin{array}{l}\text { Patient } \\
(n=150)\end{array}$ & Complication & P-value \\
\hline Weight change & & & 0.055 \\
\hline Weight gain & $87(58.0)$ & $25(28.7)$ & \\
\hline Mild loss (<5\%) & $23(15.3)$ & $5(21.7)$ & \\
\hline Moderate loss (5-15\%) & $34(22.7)$ & $14(41.2)$ & \\
\hline Severe loss (>15\%) & $6(4.0)$ & $4(66.7)$ & \\
\hline \multicolumn{4}{|l|}{ Body mass index } \\
\hline At discharge after on $1^{\circ}$ operation & & & 0.382 \\
\hline Low weight & $20(13.3)$ & $4(20.0)$ & \\
\hline Normal & $94(62.7)$ & $28(29.8)$ & \\
\hline Overweight & $33(22.0)$ & $14(42.4)$ & \\
\hline Obesity & $3(2.0)$ & $2(66.70)$ & \\
\hline Preoperative & & & 0.568 \\
\hline Low weight & $16(10.7)$ & $5(31.2)$ & \\
\hline Normal & $102(68.0)$ & $36(35.3)$ & \\
\hline Overweight & $31(20.7)$ & $7(22.6)$ & \\
\hline Obesity & $1(0.6)$ & $(0)$ & \\
\hline Pattern & & & 0.002 \\
\hline Maintenance & $108(72.0)$ & $33(30.6)$ & \\
\hline Decrease & $22(14.7)$ & $14(63.6)$ & \\
\hline Increase & $20(13.3)$ & $1(5.0)$ & \\
\hline \multicolumn{4}{|l|}{ Albumin } \\
\hline Preoperative & & & 0.747 \\
\hline Good ( $\geq 3.5)$ & $143(95.3)$ & $46(32.2)$ & \\
\hline Mild malnutrition (3.2-3.5) & $1(0.7)$ & (0) & \\
\hline Moderate loss (2.8-3.2) & $6(4.0)$ & $2(33.3)$ & \\
\hline Postoperative & & & 0.015 \\
\hline Good ( $\geq 3.5)$ & $64(42.7)$ & $13(20.3)$ & \\
\hline Mild malnutrition (3.2-3.5) & $52(34.7)$ & $19(36.5)$ & \\
\hline Moderate loss (2.8-3.2) & $23(15.3)$ & $8(34.8)$ & \\
\hline Severe malnutrition $(<2.8)$ & $11(7.3)$ & $8(72.7)$ & \\
\hline Postoperative decrement & & & $<0.001$ \\
\hline$<1.3$ & $118(78.7)$ & $26(22.0)$ & \\
\hline$\geq 1.3$ & $32(21.3)$ & $22(68.8)$ & \\
\hline
\end{tabular}

Values are presented as number (\%). 
nificant factors which were related to the occurrence of complications. An end-type ostomy as compared with a loop-type ostomy $(\mathrm{P}=0.001)$ and intraperitoneal severe adhesion $(\mathrm{P}=0.012)$ were associated with postoperative ileus. The takedown intervals from ostomy formation were significantly different, with the ileus group showing delayed takedown (30.4 \pm 9.59 vs. $20.1 \pm 1.2, \mathrm{P}=0.03)$. Operation time was longer in the ileus group (137.67 $\pm 11.02 \mathrm{~min}-$ utes vs. $105.93 \pm 5.97$ minutes). In the assessment of nutritional status, a decrease in serum albumin level $(>1.3)$ after takedown and TLC, which was checked preoperatively, were significantly related factors $(P=0.01,0.011)$. Regarding TLC analysis, however, TLC levels of both groups were within the normal nutritional range and were not considered a significant result. In the multivariable analysis, operation time longer than 2 hours was the single most significant factor $(\mathrm{P}=0.002$; odds ratio [OR], 5.7; 95\% confidence interval [CI], 3.7 to 17.8) (Table 5).

\section{Anastomotic leakage}

Leakage that would require open-abdominal reoperation occurred in five patients (3.3\%). Univariate analysis showed three related factors: hypertension, younger age, and longer operation time. The multivariable analysis model selected longer operation times (>2 hours) $(\mathrm{P}=0.003$; OR, 3.9; 95\% CI, 1.2 to 8.9) (Table 4).

\section{SSI}

Of 150 patients, 18 patients (12\%) had a SSI as a postoperative complication. Patients with takedowns of ostomy formation caused by traumatic injuries and with end-type ostomies had higher rates of SSI (Table 4). In the nutritional status assessment, preoperative overweight, a marked postoperative decrease in albumin, and a

Table 4. Univariate analysis of complications

\begin{tabular}{|c|c|c|c|}
\hline & Present & Absent & P-value \\
\hline Ileus & $\mathrm{n}=21$ & $\mathrm{n}=129$ & \\
\hline Ostomy type - end ( $n=61)$ & 16 & 45 & 0.001 \\
\hline Severe adhesion $(n=75)$ & 21 & 54 & 0.012 \\
\hline Takedown interval (wk) & $30.4 \pm 9.59$ & $20.1 \pm 1.2$ & 0.03 \\
\hline Postoperative decrement of albumin & $1.3 \pm 0.1$ & $0.9 \pm 0.2$ & 0.01 \\
\hline Pre-total lymphocyte count & $1,893.3 \pm 85.7$ & $2,382.3 \pm 155.9$ & 0.011 \\
\hline Operation time (min) & $137.7 \pm 11.0$ & $105.9 \pm 5.9$ & 0.019 \\
\hline Anastomotic leakage & $n=5$ & $n=145$ & \\
\hline Hypertension, n (\%) & $3(60.0)$ & $25(17.2)$ & 0.049 \\
\hline Age (yr) & $65.5 \pm 1.9$ & $58.7 \pm 1.6$ & 0.02 \\
\hline Operation time (min) & $160.0 \pm 8.7$ & $108.3 \pm 5.6$ & 0.02 \\
\hline Surgical site infection & $\mathrm{n}=18$ & $n=132$ & \\
\hline Preceding etiology - trauma $(n=35)$ & 5 & 30 & 0.015 \\
\hline Ostomy pattern - end $(n=61)$ & 12 & 49 & 0.002 \\
\hline Pre-body weight & $65.2 \pm 2.2$ & $58.1 \pm 1.1$ & 0.022 \\
\hline Postoperative decrement of albumin & $1.2 \pm 0.1$ & $0.92 \pm 0.05$ & 0.018 \\
\hline Pre-total lymphocyte count & $1,894.7 \pm 83.5$ & $2,407.7 \pm 197.6$ & 0.003 \\
\hline
\end{tabular}

Values are presented as mean \pm SD or number (\%).

Table 5. Multivariable analysis of complications

\begin{tabular}{llcc}
\hline \multirow{2}{*}{$\begin{array}{l}\text { Complication } \\
\text { Complication }\end{array}$} & Related factor & \multicolumn{2}{c}{ Multivariate } \\
\cline { 2 - 4 } & & P-value & OR (95\% Cl) \\
Ileus & Ostomy pattern - end & 0.021 & $2.8(1.2-6.9)$ \\
Leakage & Postoperative decrement of serum albumin concentration (>1.3) & 0.002 & $5.3(1.8-15.2)$ \\
Surgical site infection & Operation time (>2 hr) & 0.002 & $5.7(3.7-17.8)$ \\
\hline
\end{tabular}

$\mathrm{OR}$, odds ratio; $\mathrm{Cl}$, confidence interval. 
lower level of preoperative TLC were statistically significant factors (Table 4). Multivariable analysis, however, showed that a significant postoperative decrease in serum albumin concentration was the single most reliable factor for predicting SSI $(\mathrm{P}=0.001$; OR, 7.6; 95\% CI, 3.7 to 15.8 ) (Table 5).

\section{DISCUSSION}

Temporary fecal diversion is still playing a role in intestinal surgery to avoid an anastomosis or to reduce the risk of leakage after an anastomosis. Once an ostomy is created, the timing of ostomy takedown is variable and depends largely on a variety of factors. An overall incidence of complications as high as 5 to $39 \%$ has been reported; of this, SSI is the most common, 7 to $29 \%[4,5]$. In their study of Hartmann's reversal, Boland et al. [15] noted that reversal is associated with a host of minor and major complications. These authors reported a $40 \%$ minor complication rate, and, concurrently, documented a $38 \%$ major complication rate, including myocardial infarctions, leaks, and respiratory failures. They encountered one death, and $28.6 \%$ of the patients $(n=10)$ were left with ostomies at the end of their respective takedowns. Our data also show a high rate of complications, overall $32.1 \%$. However, data showed that the overall risk of serious complications was low, $3.6 \%$, particularly if local wound complications were not taken into consideration. In the National Nosocomial Infection Surveillance, risk factors for the development of a SSI include ASA grade, contaminated or dirty wounds, and the duration of procedure [16]. Other risk factors described include increased BMI, emergency surgery, surgeries involved, and blood loss [11]. To date, there are relatively few studies examining the influence of a patient's perioperative nutritional status on the development of SSI and overall complications following stoma take-down.

The type of ostomy (loop vs. end) depends primarily on functional purpose and the type of procedure performed. Loop-type ostomies are generally used as proximal diversions for protection of distal anastomoses, which are usually performed in an elective surgery setting. End-type ostomies are used after bowel resection in order to fully avoid the risks of performing a primary anastomosis, usually in the setting of emergent surgery [17-19]. Takedown of an end-type ostomy showed a long operation time, a larger amount of intraoperative bleeding and a high rate of complications in our data. Based on this finding, the type of ostomy should be carefully selected at the time of the initial surgery. Furthermore, the literature notes several small studies that reported fewer ostomy-related complications after a loop ileostomy. Loop transverse colostomies are associated with more complications, such as incisional hernias, parastomal hernias, prolapses, and fecal fistulas than loop ileostomies [20].

In patients with malnutrition, perioperative nutritional supplementation has been used to decrease the risk of postoperative anastomotic leakage and infectious complications [21]. Even in patients without malnutrition, some risk of SSI exists in a clean-contami- nated surgical procedure, such as colorectal surgery [22]. Horie et al. [23] reported that administration of preoperative 5-day oral immunonutrition of the IMPACT Japanese version $(750 \mathrm{~mL} /$ day $)$ to colorectal patients without malnutrition was associated with a high compliance and effective prevention of SSI. In their data, total protein did not show a significant increase in the immunonutrition group. However, the mean albumin level at 3 days after surgery was significantly higher for the immunonutrition group than for the control group. Our data show that temporary ostomies did not result in serious malnutrition. However, downgrading of BMI shift during the observation period was associated with a higher rate of complications. Of particular interest, a postoperative shift in the serum albumin concentration $(\geq 1.3 \mathrm{mg} / \mathrm{dL}$ decrease) was a significant predictor of susceptibility to postoperative complications. In some literature, albumin is the most commonly used indicator of a patient's nutritional status [10-13]. In acute illness, there is a reduction due to alterations in hepatic metabolism and loss of albumin into the interstitium. Serum albumin is a reliable and reproducible predictor of surgical risk and has a close correlation with the degree of malnutrition [24]. In this study, there was a different point compared with these reports. A significant postoperative decrease in the serum albumin concentration was more reflective of complications than preoperative concentrations. While in preoperative nutritional assessment, there was no difference between ostomy take-downs because it did not always allow patients with ostomies to completely recover and regain their fundamental premorbid status, which would increase their chance of a better outcome [25]. For example, reoperations in patients after sepsis and multiple laparotomies are technically demanding due to the development of multiple firm adhesions and sometimes even a "frozen" abdomen, which in turn may lead to a higher rate of complications [26, 27]. Fundamentally, recovered patients could show tolerance against this stressful challenge while potentially, malnutritious patients with ostomies could be readily fragile, possibly resulting in a larger drop in the shift of albumin level.

Hypoalbuminemia is associated with poor surgical outcome [28, 29]. A decrease in albumin from 45 to $21 \mathrm{~g} / \mathrm{L}$ is associated with an increase in morbidity from 10 to $65 \%$ [13]. However, this may be attributed to perioperative fluid overload and hemodilution, these factors being associated with poorer outcomes [30]. Our study has highlighted a postoperative decrease in albumin as a risk factor for SSI and overall complications. The multivariate analysis showed that a postoperative decrease of $<1.3$ increased the risk of SSI and overall complications by 7.6 and 5.3 fold, respectively. Some literature on SSI reported that hypoalbuminemia was associated with poor tissue healing, impaired collagen synthesis and granuloma formation in surgical wounds and that those factors caused delayed healing and increased dead space in wounds [31]. Also, hypoalbuminemia is associated with dysfunction of innate immune response and causes impairment of macrophage activation. Combined, these factors could promote the development of SSI and infectious complications in patients with a postsurgically severe 
hypoalbuminemic status.

In conclusion, a postoperatively significant decrease in the serum albumin concentration is an independent risk factor for the development of overall complications, particularly SSI. Surgeons should be aware of the risk of potential malnutrition in patients with an ostomy, and when the postoperative decrease of albumin is intense, they should manage the patient with caution. While ostomies may not essentially result in serious malnutrition, marked weight loss such as BMI downgrading may be associated with the development of complications. In this study, a postoperative significant decrease in the serum albumin concentration was the single most reliable predictor for SSI and was available as one of the risk factors for predicting several postoperative complications

\section{CONFLICT OF INTEREST}

No potential conflict of interest relevant to this article was reported.

\section{REFERENCES}

1. Cromar CD. The evolution of colostomy. Dis Colon Rectum 1968; 11:256-80.

2. Shellito PC. Complications of abdominal stoma surgery. Dis Colon Rectum 1998;41:1562-72.

3. Hines JR, Harris GD. Colostomy and colostomy closure. Surg Clin North Am 1977;57:1379-92.

4. Hackam DJ, Rotstein OD. Stoma closure and wound infection: an evaluation of risk factors. Can J Surg 1995;38:144-8.

5. Pokorny RM, Heniford T, Allen JW, Tuckson WB, Galandiuk S. Limited utility of preoperative studies in preparation for colostomy closure. Am Surg 1999;65:338-40.

6. Beck PH, Conklin HB. Closure of colostomy. Ann Surg 1975;181: 795-8.

7. Kim DD, Kim EJ, Lee HO, Park IJ, Kim HC, Yu CS, et al. The complications of stoma take-down. J Korean Soc Coloproctol 2008; 24:83-90.

8. Harold DM, Johnson EK, Rizzo JA, Steele SR. Primary closure of stoma site wounds after ostomy takedown. Am J Surg 2010;199: 621-4.

9. Grimble GK. Dietary nucleotides and gut mucosal defence. Gut 1994;35(1 Suppl):S46-51.

10. Sung J, Bochicchio GV, Joshi M, Bochicchio K, Costas A, Tracy K, et al. Admission serum albumin is predicitve of outcome in critically ill trauma patients. Am Surg 2004;70:1099-102.

11. Blumetti J, Luu M, Sarosi G, Hartless K, McFarlin J, Parker B, et al. Surgical site infections after colorectal surgery: do risk factors vary depending on the type of infection considered? Surgery 2007;142: 704-11.

12. Lohsiriwat V, Chinswangwatanakul V, Lohsiriwat S, Akaraviputh T, Boonnuch W, Methasade A, et al. Hypoalbuminemia is a predictor of delayed postoperative bowel function and poor surgical outcomes in right-sided colon cancer patients. Asia Pac J Clin
Nutr 2007;16:213-7.

13. Gibbs J, Cull W, Henderson W, Daley J, Hur K, Khuri SF. Preoperative serum albumin level as a predictor of operative mortality and morbidity: results from the National VA Surgical Risk Study. Arch Surg 1999;134:36-42.

14. Garrard CL, Clements RH, Nanney L, Davidson JM, Richards WO. Adhesion formation is reduced after laparoscopic surgery. Surg Endosc 1999;13:10-3.

15. Boland E, Hsu A, Brand MI, Saclarides TJ. Hartmann's colostomy reversal: outcome of patients undergoing surgery with the intention of eliminating fecal diversion. Am Surg 2007;73:664-7.

16. Smyth ET, Emmerson AM. Surgical site infection surveillance. J Hosp Infect 2000;45:173-84.

17. Fonkalsrud EW, Thakur A, Roof L. Comparison of loop versus end ileostomy for fecal diversion after restorative proctocolectomy for ulcerative colitis. J Am Coll Surg 2000;190:418-22.

18. Phang PT, Hain JM, Perez-Ramirez JJ, Madoff RD, Gemlo BT. Techniques and complications of ileostomy takedown. Am J Surg 1999;177:463-6.

19. Perez RO, Habr-Gama A, Seid VE, Proscurshim I, Sousa AH Jr, Kiss DR, et al. Loop ileostomy morbidity: timing of closure matters. Dis Colon Rectum 2006;49:1539-45.

20. Edwards DP, Leppington-Clarke A, Sexton R, Heald RJ, Moran BJ. Stoma-related complications are more frequent after transverse colostomy than loop ileostomy: a prospective randomized clinical trial. Br J Surg 2001;88:360-3.

21. Mullen JL, Buzby GP, Matthews DC, Smale BF, Rosato EF. Reduction of operative morbidity and mortality by combined preoperative and postoperative nutritional support. Ann Surg 1980;192: 604-13.

22. Anaya DA, Dellinger EP. Surgical infections and choice of antibiotics. In: Townsend CM, Beauchamp RD, Evers BM, Mattox KL, editors. Sabiston textbook of surgery: the biological basis of modern surgical practice. 17th ed. Philadelphia: Elsevier; 2004. p. 257-82.

23. Horie H, Okada M, Kojima M, Nagai H. Favorable effects of preoperative enteral immunonutrition on a surgical site infection in patients with colorectal cancer without malnutrition. Surg Today 2006;36:1063-8.

24. Fuhrman MP, Charney P, Mueller CM. Hepatic proteins and nutrition assessment. J Am Diet Assoc 2004;104:1258-64.

25. Martinez JL, Luque-de-Leon E, Andrade P. Factors related to anastomotic dehiscence and mortality after terminal stomal closure in the management of patients with severe secondary peritonitis. J Gastrointest Surg 2008;12:2110-8.

26. Banerjee S, Leather AJ, Rennie JA, Samano N, Gonzalez JG, Papagrigoriadis S. Feasibility and morbidity of reversal of Hartmann's. Colorectal Dis 2005;7:454-9.

27. Shellito PC. Complications of abdominal stoma surgery. Dis Colon Rectum 1998;41:1562-72.

28. Sungurtekin H, Sungurtekin U, Balci C, Zencir M, Erdem E. The influence of nutritional status on complications after major intraabdominal surgery. J Am Coll Nutr 2004;23:227-32. 
29. Inoue Y, Miki C, Kusunoki M. Nutritional status and cytokinerelated protein breakdown in elderly patients with gastrointestinal malignancies. J Surg Oncol 2004;86:91-8.

30. Rahbari NN, Zimmermann JB, Schmidt T, Koch M, Weigand MA, Weitz J. Meta-analysis of standard, restrictive and supplemental fluid administration in colorectal surgery. Br J Surg 2009;96:331-41.
31. Hennessey DB, Burke JP, Ni-Dhonochu T, Shields C, Winter DC, Mealy K. Preoperative hypoalbuminemia is an independent risk factor for the development of surgical site infection following gastrointestinal surgery: a multi-institutional study. Ann Surg 2010; 252:325-9. 